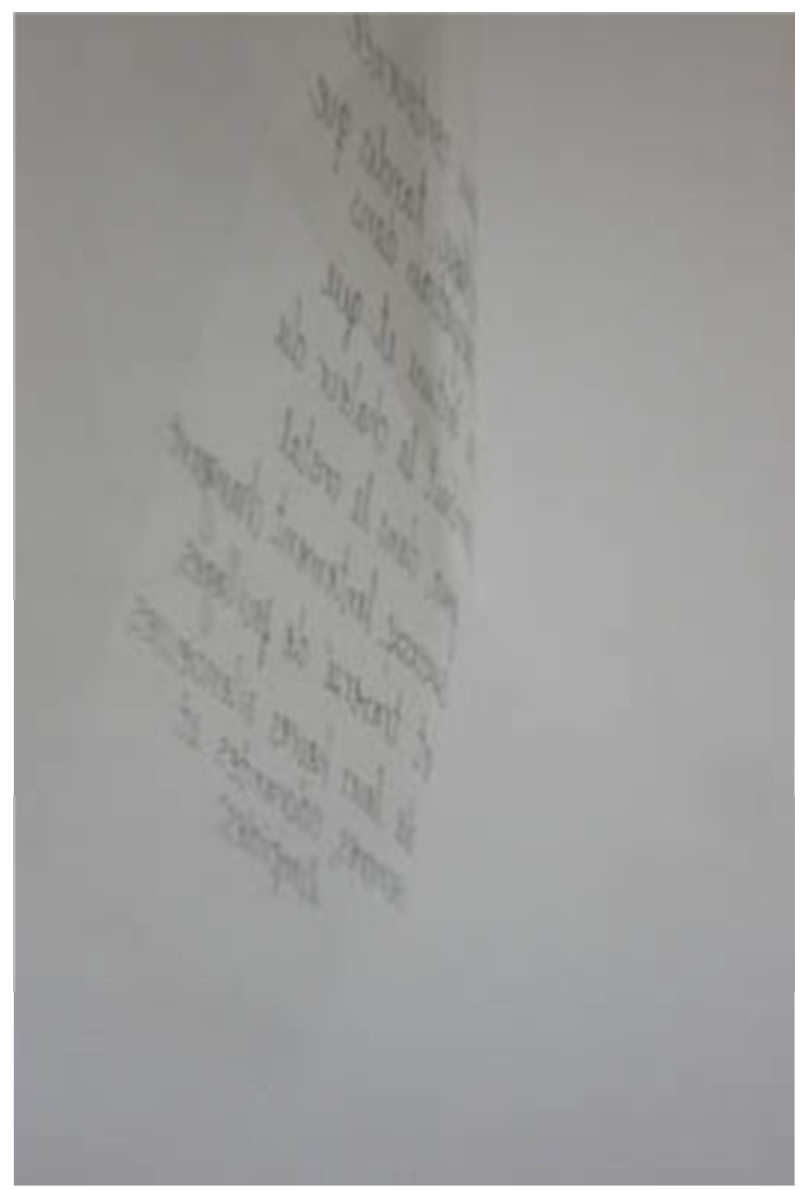

Ilustração Vivian Margutti

\title{
la chaleur du jour
}

\section{Texto de Proust adaptado e traduzido por Vivian Margutti}

Mestre em Teoria da Literatura pela Faculdade de Letras da UFMG e doutoranda em Literatura Comparada pela mesma faculdade. 
Txt: Leituras Transdisciplinares de Telas e Textos, Belo Horizonte, v.3, n.5, p.80-83, 2007

pouco a pouco,

contornado e enclausurado,

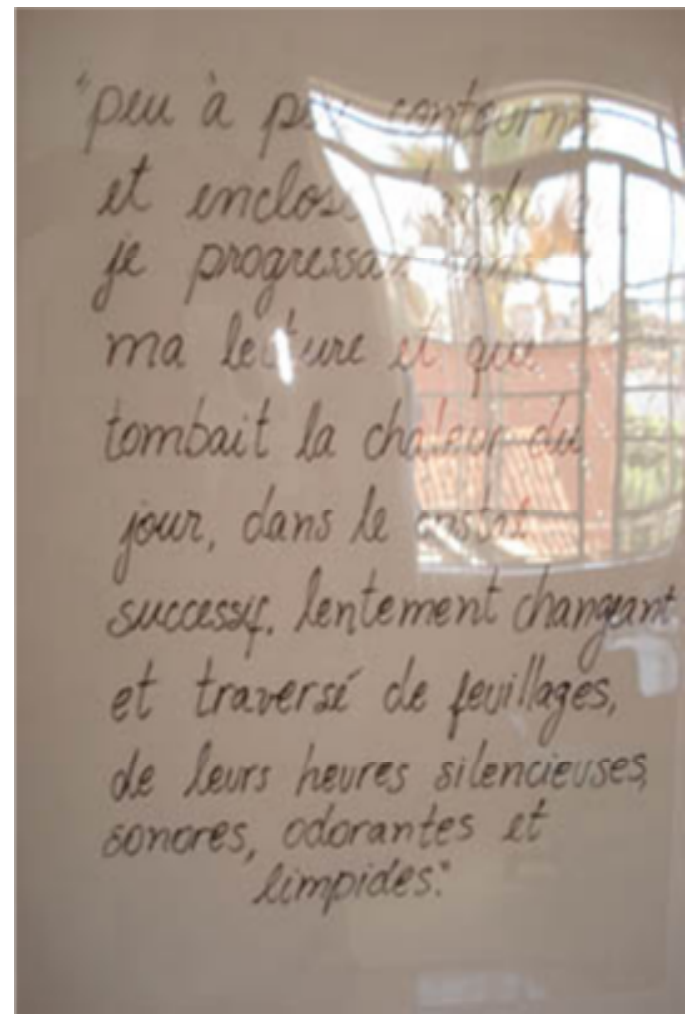

prosseguia em minha leitura,

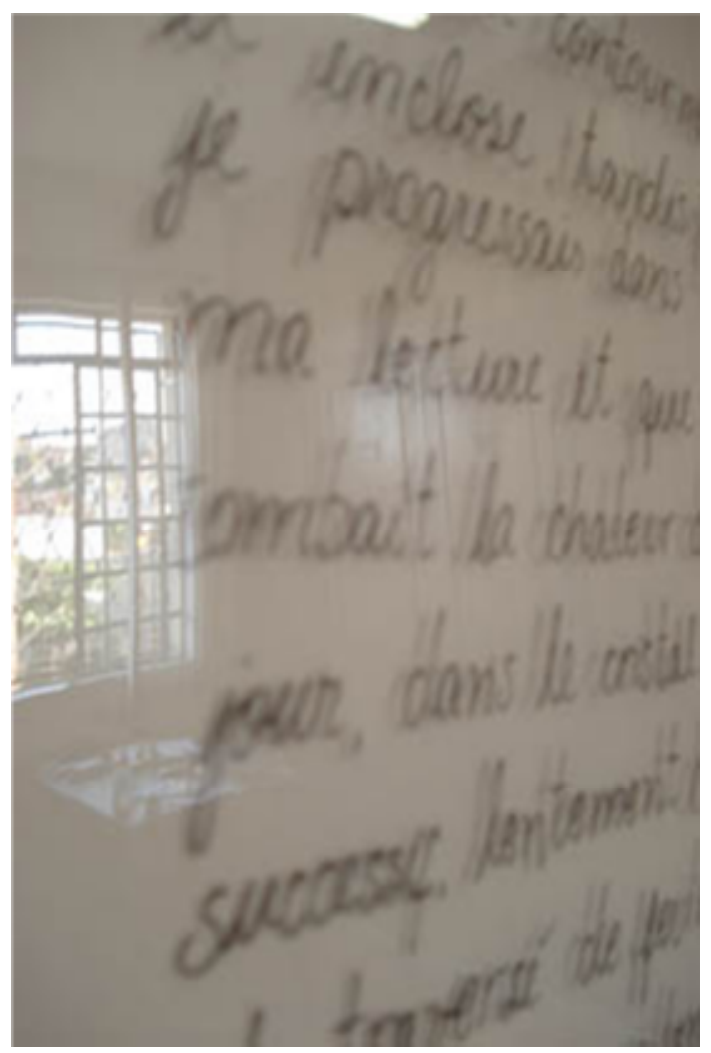


Txt: Leituras Transdisciplinares de Telas e Textos, Belo Horizonte, v.3, n.5, p.80-83, 2007

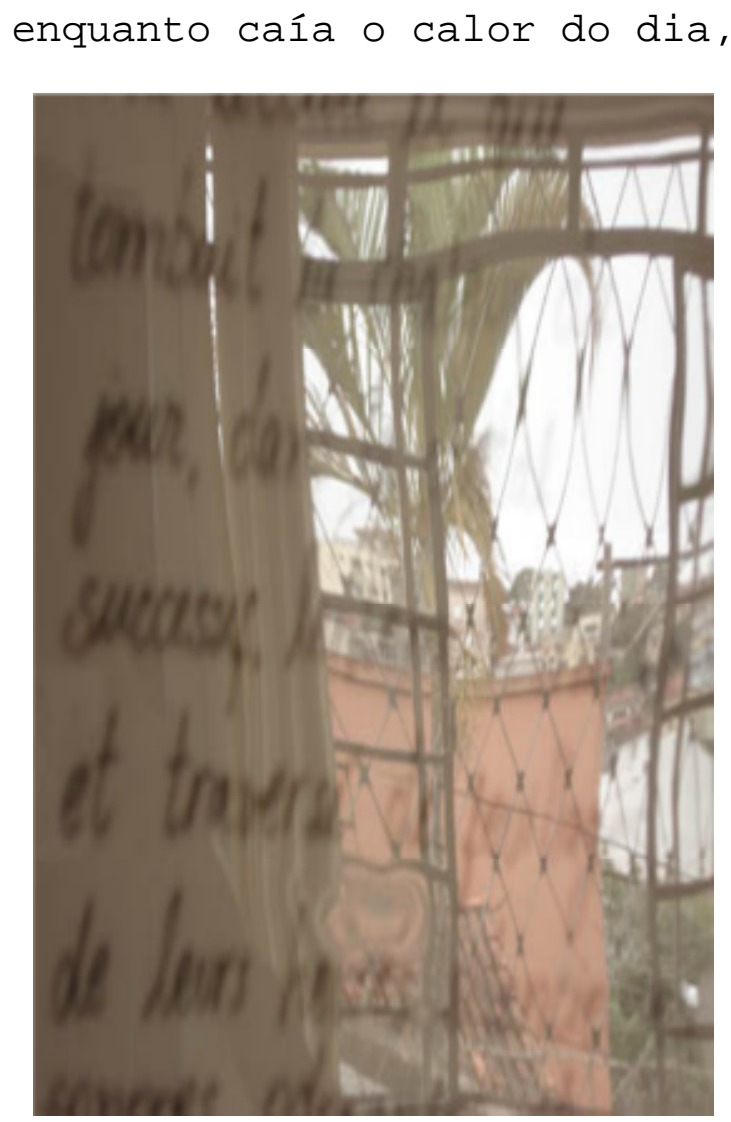

no cristal sucessivo,

lentamente cambiante

perpassado por folhas,

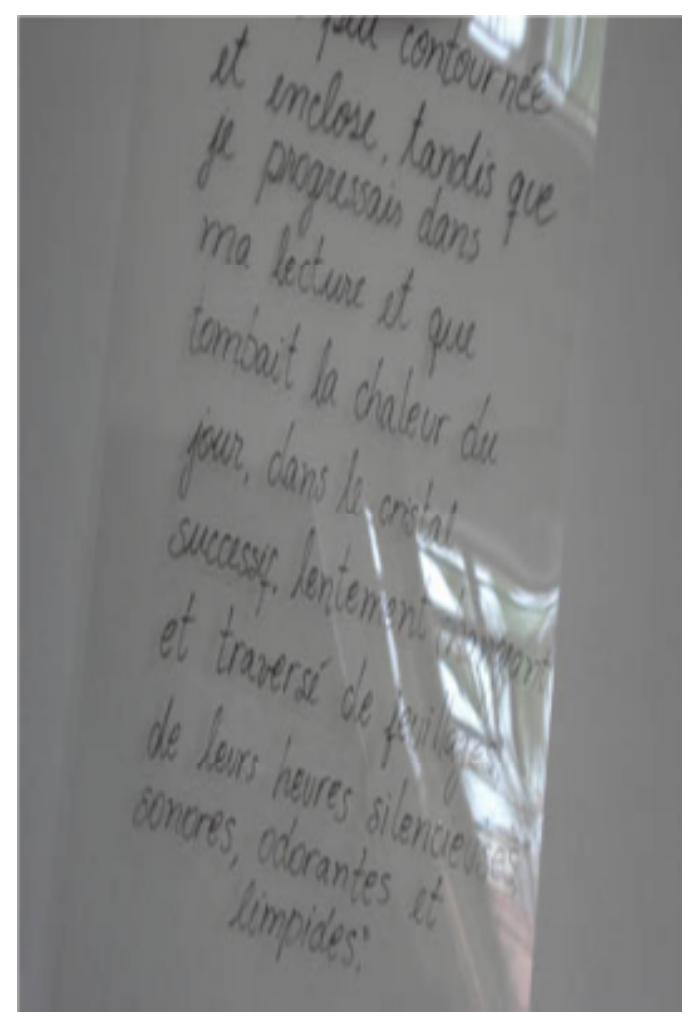


Txt: Leituras Transdisciplinares de Telas e Textos, Belo Horizonte, v.3, n.5, p.80-83, 2007

suas horas silenciosas,

sonoras,

perfumadas e

límpidas.

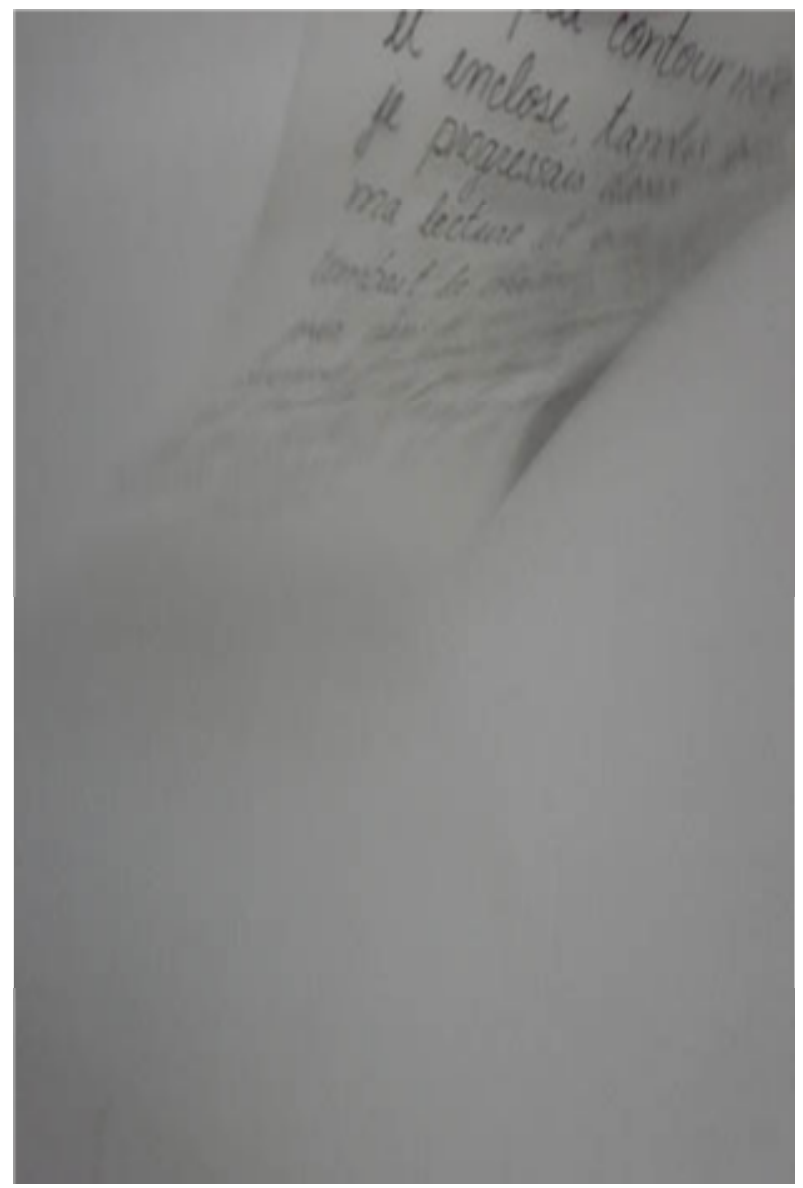

